\title{
Ectopic Varices and Collaterals Development after Band Ligation Treatment in a Patient with Portal Hypertension
}

\author{
Jean Louis Frossard Mariam Seirafi Laurent Spahr \\ Division of Gastroenterology and Hepatology, Geneva University Hospital, \\ Geneva, Switzerland
}

\section{Key Words}

Portal hypertension $\cdot$ Duodenal varice $\cdot$ Ectopic varice

\begin{abstract}
Esophageal and gastric varices may complicate the course of cirrhosis as a direct consequence of portal hypertension. Variceal hemorrhage has been reported to occur in 25-40\% of patients with cirrhosis [Gastroenterol Clin North Am 1992;21:149-161]. Occasionally, varices develop at sites other than the esophagus and are detected either when they bleed or incidentally during upper or lower endoscopy [Eur J Gastroenterol Hepatol 2006;18:1155-1160; Digestion 2000;61:149-150]. Endoscopic treatment is often unsuccessful in these cases, and traditional treatment is usually surgical, while it has been suggested that bleeding can also be controlled by a transjugular intrahepatic portosystemic shunt (TIPS) [Endoscopy 1995;27:626-627]. Moreover, esophageal band ligation may interfere with the collateral web. We here report a case of an ectopic duodenal varix and the development of a large collaterals web that appeared after band ligation.
\end{abstract}

\section{Case Report}

A 57-year-old diabetic man presented with upper gastrointestinal hemorrhage. He was known to have nonalcoholic steatohepatitis with cirrhosis and had suffered in the past two years from esophageal varix ruptures that were successfully treated using band ligation. Upon admission, hemoglobin level was $8.1 \mathrm{~g} / \mathrm{dl}$ and mean corpuscular volume $71 \mu \mathrm{m}^{3}$. Initial endoscopy of the upper gastrointestinal tract showed fibrous varices and grade 1 esophageal varices without any stigmata of recent hemorrhage, a small fundic varix that was actively bleeding and treated using band ligation. When reaching the duodenum, we found a large submucosal vermicular mass located in the first and second duodenum (fig. 1a, arrows) that had not beenpresent at the first endoscopy performed at the first variceal bleeding rupture two years earlier. Colonoscopy identified several nonbleeding vascular ectasias and several rectal varices. Second look endoscopy performed $48 \mathrm{~h}$ after admission confirmed the presence of grade 1 esophageal varices and the large submucosal blue-appearing vermicular mass located in the duodenum. 
Further investigation was performed using ultrasonography miniprobe in the duodenum (fig. 1b, arrows) and in the esophagus while the endoscope was gently retrieved. Endoscopic ultrasonography (EUS) identified a large paraduodenal varix perforating the duodenal wall that protruded into the duodenal lumen (fig. 1b, arrows). EUS also identified a large collateral web of vessels located around the esophagus and which corresponded to a large portosystemic venous web of collaterals (fig. $2 a$ ) whose size may have been influenced after band ligation. This web was of particular size at the esogastric junction (fig. 2b). The size of the duodenal varix urged us to propose a portal decompression by a TIPS instead of endoscopic therapy. At follow-up visit 30 days later, the patient had no signs of further bleeding and his hemoglobin level was $11.9 \mathrm{~g} / \mathrm{dl}$. Furthermore, the patient did not develop hepatic encephalopathy.

\section{Discussion}

Esophageal varices are responsible for up to $70 \%$ of all upper gastrointestinal bleeding episodes in patients with portal hypertension. A variceal source should always be suspected in any cirrhotic patient with acute upper gastrointestinal bleeding [1]. Diagnosis is usually established by the emergency endoscopist facing either active bleeding from a varix, or white nipple or clot adherent to a varix, and presence of varices without other potential sources of bleeding. The incidence of ectopic variceal rupture is as high as $1-5 \%$ of all variceal bleedings [2]. Ectopic varices are defined as natural portosystemic shunt leading to the appearance of venous collaterals anywhere in the abdomen. However, their appearance has been reported to be more frequent in cirrhotic patients having a history of previous abdominal surgery [3]. Furthermore, the prognosis from bleeding ectopic varices may be poor, with one study quoting more than $40 \%$ mortality at initial bleed from duodenal varices [4].

Our patient had several complications of portal hypertension including esophageal, gastric ectopic and rectal varices as well as portal gastropathy and colopathy. This particular case illustrates a typical ultrasonographic image of duodenal varice that was initially suspected at the first emergency endoscopy. It also illustrates the fact that previous band ligation treatment may influence the natural history of portosystemic shunt with the development of ectopic varices and participate to increase the size of the collateral web around the esogastric junction. The management of ectopic varices is difficult and must be performed by a multidisciplinary team. In the current case, sclerotherapy as well as band ligation were not chosen because we thought that if the entire varix could not be treated in one session, we might cause a wide defect in the varix that could precipitate a severe bleeding. A TIPS was chosen instead in our patient because this technique is extremely effective in controlling variceal bleeding with a control rate approaching $95 \%$. However, due to worsening of liver function and encephalopathy, mortality remains unfortunately high [5]. Indeed, the 7 days and 6 month rates of survival after TIPS for ectopic variceal bleeding are 96 and 65\%, respectively [6]. 


\begin{tabular}{r|l|l|l} 
Case Reports in & $\begin{array}{l}\text { Case Rep Gastroenterol 2008;2:380-383 } \\
\text { D0I: 10.1159/000155148 }\end{array}$ & Published online: November 7, 2008 & $\begin{array}{l}\text { O 2008 S. Karger AG, Basel } \\
\text { ISSN 1662-0631 } \\
\text { www.karger.com/crg }\end{array}$ \\
\hline
\end{tabular}

Fig. 1. a Serpiginous blue mass in the duodenum at endoscopy. b Duodenal vessel that perforates the duodenal wall with protrusion into the digestive lumen as seen at EUS.
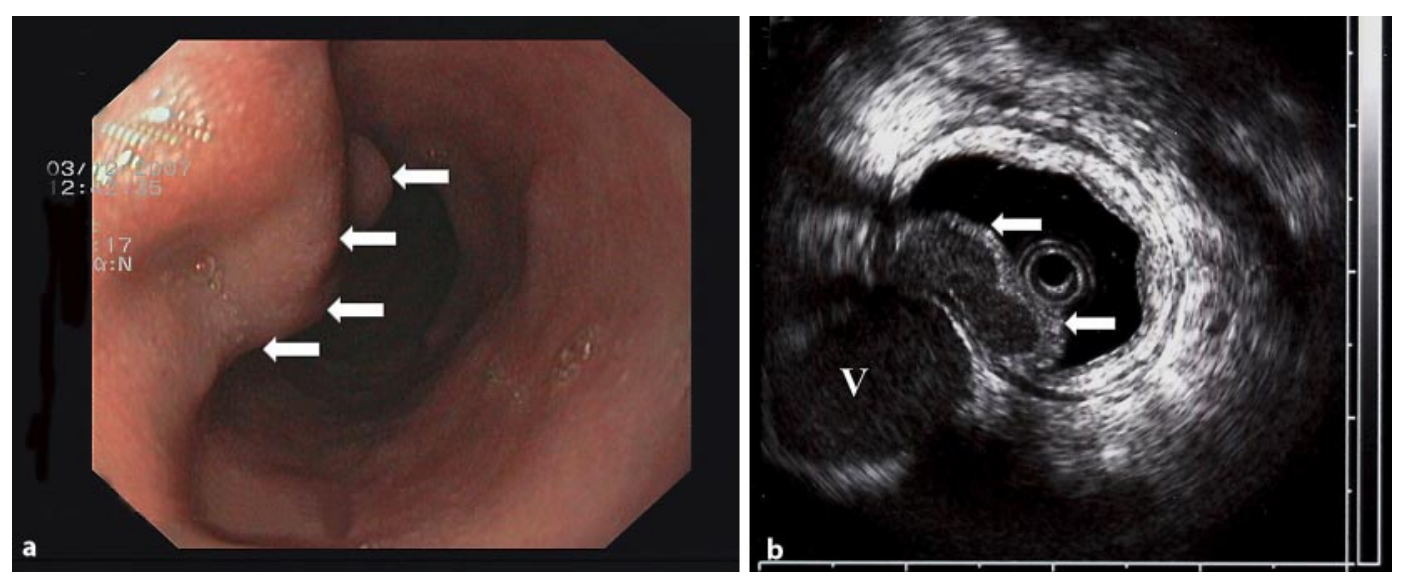

Fig. 2. a Moderate web of periesophageal collaterals (arrows). b Massive web of portosystemic collaterals developed around the esogastric junction as seen at EUS.
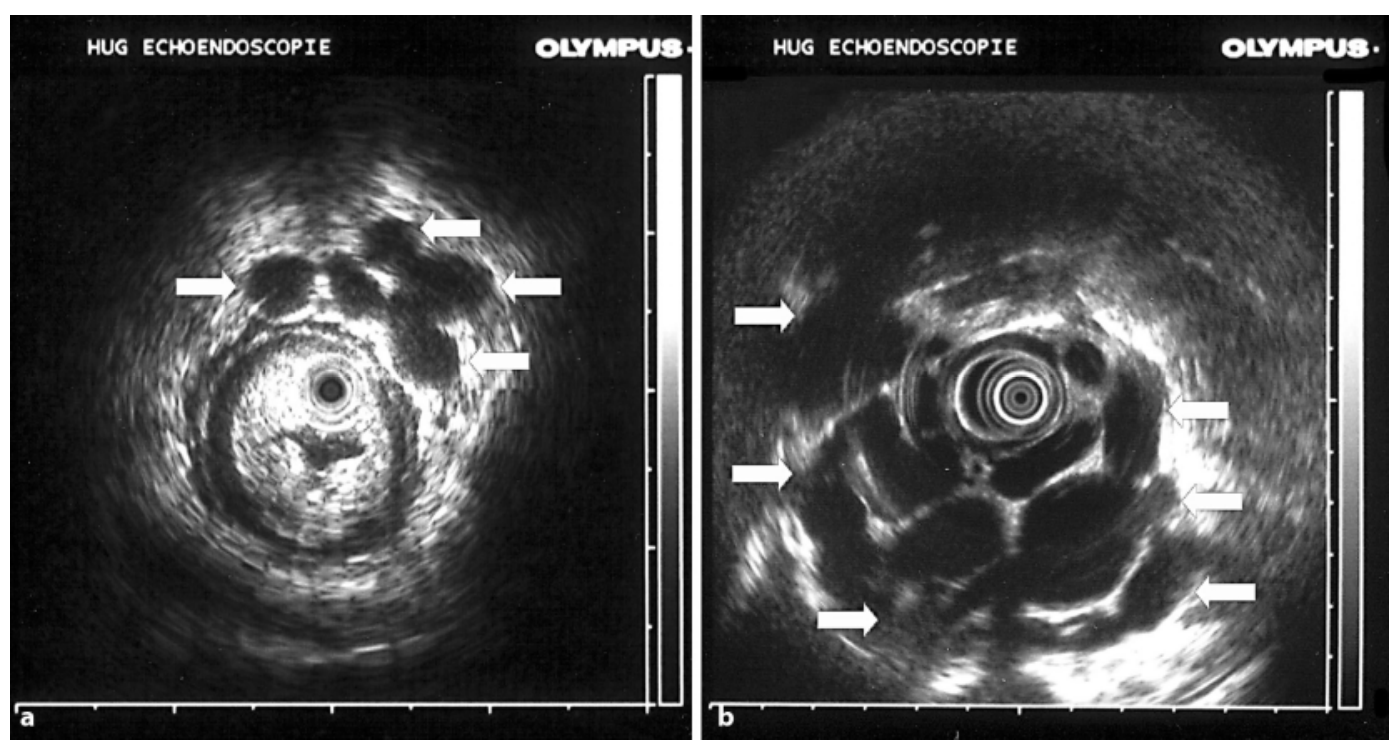


\section{References}

-1 D’Amico G, De Franchis R: Upper digestive bleeding in cirrhosis. Post-therapeutic outcome and prognostic indicators. Hepatology 2003;38:599612.

2 Norton I, Andrews J, Kamath P: Management of ectopic varices. Hepatology 1998;28:1154-1158.

-3 Grundfest-Broniatowski S, Fazio V: Conservative treatment of bleeding stomal varices. Arch Surg 1983;118:981-985.

4 Khouqeer F, Morrow C, Jordan P: Duodenal varices as a cause of massive upper gastrointestinal bleeding. Surgery 1987;102:548-552.

5 D'Amico G, Pagliaro L, Bosch J: The treatment of portal hypertension: a meta-analytic review. Hepatology 1995;22:332-354.

6 Vangeli M, Patch D, Terreni N: Bleeding ectopic varices - treatment with transjugular intrahepatic portosystemic shunt (TIPS) and embolisation. J Hepatol 2004;41:560-566. 